\title{
Surgery-for-Life: \\ Aging, Sexual Fitness and Self-Management in Brazil
}

\author{
Alexander Edmonds \\ Professor of Social and Medical Anthropology \\ University of Edinburgh
}

\begin{abstract}
This article draws on ethnographic fieldwork on plastic surgery to explore tensions in aging norms and ideals for women in Brazil. I situate my analysis in relation to debates about a "de-chronologized life course." Some scholars argue that the life course in late capitalism has become less standardized. In this account, chronological age diminishes in importance as consumers are defined by life style choices available to all ages and the period of youth extends into middle age and beyond. In Brazil consumers embrace plastic surgery as a means to "manage" aging, mental wellbeing, and reproductive and sexual health. This promise of a flexible and optimized aging trajectory seems to echo the notion of a de-chronologized life course. I argue, however, that medical discourse and patients' accounts show ambivalence about aging and conflicts in the ideal of medically-managed sexual fitness for women. Drawing on analysis of changes in family structure and women's health regimes, I argue that passage through the life course, rather than becoming more flexible, is in some ways becoming more rigidly defined by biological processes.
\end{abstract}

Keywords: Aging, plastic surgery, de-chronologized life course, sexual fitness, self-management,

\section{INTRODUCTION}

Nelson [Rodriguez, the playwright] said to me, 'Tatiana, only assholes age. Everyone else becomes wiser.' This is very true. If you are super happy, have an active life, and a wrinkle bothers you, why not do something about it? That's different than having plástica out of bitterness. Aging is not cool.

\section{-- Tatiana, Brazilian plastic surgery patient}

Such a breezy acceptance of "plástica" has become common in Brazil as the country experiences a boom in cosmetic surgery. Tatiana's comment that "aging is not cool" also points to new ideals of aging that have been popularized in industrialized societies since the 1980s.
The terms "successful aging," "new age," and "third age" reflect an optimistic view of aging as a process that can be managed to maintain not just physical health but also mental wellbeing, social engagement, and sexual fitness. This vision of aging has been described as an inspiring ideal that enables the elderly to counteract social isolation -- but also as an ideology that masks structural changes in the life course in late capitalism, not all of which are positive. In this article I draw on ethnographic fieldwork on plastic surgery to explore tensions in ideals and norms of aging in Brazil.

I situate this analysis theoretically in relation to a debate in gerontology about the "de-chronologization" of the life 
course. Scholars have argued that passage through the life course in late or post-Fordist capitalism has become less standardized (Debert 2011, Macmillan 2005, Moody 1993). The thesis of a "de-chronologized life course" builds on research analyzing historical changes in the life course in western societies (Brückner and Mayer 2005, Kohli 2007, Held 1986). In the transition from a pre-modern to modern period the life course became more standardized, or in the expression of Kohli and Meyer (1986), there was a "chronologization of life." This was a multidimensional transformation in the structures and experiences of aging. Mass education and an industrial labor market divided the life course into distinct phases: student, worker, pensioner. Identity became less defined by family position than by rights and duties specified by the state.

The modern life course, some argue, has now been superseded by a "postmodern life course" in "which chronological age loses its relevance" (Featherstone and Hepworth 1991, Debert 2011, 6). Periods of work, leisure and education become intertwined as workers adjust to a dynamic labor market. The consumer is defined more by lifestyle choices available to all ages than by an ageddefined role in the productive order. Sexual norms have become less linked to age with the rise of serial monogamy and divorced men and women who date in middle and old age (Bruckner and Mayer 2005). Youth extends into middle age, middle age blurs into old age.

In this article I analyze the thesis of a "postmodern," de-chronologized life course in light of the experiences of Brazilian plastic surgery patients. Consumers from a broad socioeconomic spectrum embrace plástica as a means to manage psychological and women's health. Some patients view it as a way to correct aesthetic damage attributed to childbirth, breastfeeding and menopause. Other women say it enables them to "look as young as they feel," manage sexual relationships, and maintain a youthful lifestyle throughout their lives. Plastic surgery's promise of a flexible and optimized aging trajectory seems to reflect the notion of a de-chronologized life course. One problem with the term "postmodern life course," however, is that it mirrors the ideal of successful aging that is promoted by the anti-aging industry. While plástica generally has a "sex positive" discourse, a closer look at medical practices shows major tensions in new aging and sexual norms.
A rich literature in symbolic anthropology has explored how initiations, marriage ceremonies, funerals and other rites of passage "move" individuals and groups through life stages in ways that culturallly meaningful. In Brazil and other industrialized countries there are of course many such rites and ceremonies, often with Christian roots but distinctly secular expression: such as the 15th birthday party, weddings, baby showers, and increasingly since it was legalized in 1976, divorce. The experience of passage through the life cycle, however, I argue is becoming mediated by medical practices that are used to manage women's reproductive and sexual health. I analyze how plastic surgery contributes to a biologized experience of aging that radically reduces the social persona to a sexual, reproductive and aging body defined in physiological terms.

This article explores the dialectic between the erasure of biological aging and its inscription on the body. I discuss how plástica addresses an "aging subject" made responsible for managing psychological health and well being through aesthetic and therapeutic techniques. But while this medical practice seems to promise an extension of youth into middle age and beyond, it also makes the "problem of aging" start early in life as younger patients plan "preventive surgeries." While it inspires affects like hope and happiness, aging continues to provoke anxiety and disgust. Plastic surgery is not just a means of selfmanagement, but a way to manage sexual relationships as family structures change. Some women see themselves as competing in a market where youth is sexual capital that continually loses value. In this medical and social context passage through the life course, rather than becoming more flexible, is in some ways becoming more rigidly defined by biological processes.

\section{Plástica, Rejuvenation and the "Mask Of AgING"}

Brazil is the world's second biggest cosmetic surgery market (after the US). Mainstream news media, telenovelas, blogs, and entertainment magazines widely endorse plástica and present it as a routine consumer service. In the private sector cosmetic surgery became more available to a growing middle class after the stabilization of inflation in the 1990s. Remarkably, plástica has also come within reach of patients from across the socioeconomic spectrum. Credit 
plans allow patients to make small monthly payments and some are marketed to "maids and secretaries" (the latter are often paid a very low, subsistence wage). Some hospitals in the ailing public health system also offer free cosmetic operations. ${ }^{1}$ While the SUS (public health care system) did not directly authorize comsetic surgeries (except for a few procedures), chief surgeons in some hospitals were able to successfully argue that residents-in-surgery need training in cosmetic techniques. Some doctors also maintain that both reconstructive and cosmetic surgeries are a powerful means of psychological healing and thus should be offered to what they call the povão, the "common people." Surgeons from Latin America, Europe and elsewhere come to train in these residency programs where long lines of patients provide opportunities for intensive practice. ${ }^{2}$

I undertook ethnographic fieldwork in plastic surgery clinics, interviewed surgeons and patients from a range of socioeconomic backgrounds, and researched sites that play a central role in the production and consumption of beauty, such as television studios and advertising agencies. This research was conducted primarily in Rio de Janeiro intermittently for approximately two years. I have given a fuller ethnographic account of this fieldwork and the lives of patients and surgeons (see Edmonds 2009, 2010). Here I explore what plastic surgery reveals about changing aging and sexual norms in Brazil.

Many operations are seen to "work" on the aging body. Surgeons present facelifts and eyelid surgery as "rejuvenation" - even if a few doctors are critical of this promise. One senior surgeon became so exasperated by patients with "unrealistic demands" that he complained: "If I operate on a woman who is old and ugly, she is going to continue old and ugly, but with her skin stretched. 'How many years am I going to rejuvenate, doctor?' they ask me. And I say, 'I'm not going to operate on your heart, operate on your liver, I'm not going to operate on anything, I'm going to stretch the skin of your face!'” Operations performed on the body are also seen to counter aging effects. Abdominoplasty, breast and buttocks lifts, liposuction, and genital surgeries "correct" changes blamed on childbirth, breast feeding or menopause, and thus "reverse the clock" - a frequent metaphor used to describe plástica's effects. A few surgeries are motivated primarily by dissatisfaction with the size or shape of a body part, and are thus not directly linked to aging (such as rhinoplasty or some kinds of breast surgery). But even breast surgery -- both enlargement and reduction procedures -- often aims to project the breast and counter perceived effects of aging. The goals of aesthetic improvement and rejuvenation are also intertwined since women's beauty norms strongly stress youthfulness.

Surgeons and patients view the rejuvenating effects of plástica as a powerful means of improving psychological well being. A key term in medical discourse and patients' testimonials is auto-estima ("self-esteem"). Regardless of whether patients said they had "good" or "bad" autoestima, they saw plástica as a legimate means to boost it. One woman I met in a public hospital said simply: "It's psychological. I think that for any woman who does plástica these days, it's more psychological than anything." While patients gave different reasons for "low selfesteem," many said they felt their outer appearance did not match their sense of self. Glaucia was as comfortable discussing plastic surgery as Lacananian psychoanalysis. In her early 50s, she has two adult children and a namorado (boyfriend). She described the effects of her multiple operations: "The moment you see that you're young again is really good, because in reality the spirit of a person does not age. What ages is the shell (caraça), nê? If you have a young spirit and have those aging problems, it's terrible. I'm young, I'm a girl (garota)."

Similarly, Lídia, a middle-aged facelift patient, said:

Every time that I got up and looked at myself in the mirror I had this desire [for surgery] because I said, "It's not possible. Ah, to wake up with this face, I don't want to wake up anymore, no." [laughs] Because when I put on make-up everything's more ... but it's the moment when you wake up, nê?

For Lídia a facelift did not reflect a desire to "be someone else," but to "look like herself."

In Freud's (2003) account, recognizing oneself in what at first seems to be a strange image in a mirror or photograph elicits an "uncanny" feeling. This uncanny double recalls Lídia's experience of not recognizing herself in the mirror, as if the aged face confronting her was both familiar and monstrously unfamiliar. For some patients their "naturally" aged appearance can seem more foreign to them than an "artificially" enhanced one. One critique of plastic surgery is that it distorts identity or causes selfalienation. But for many patients aging itself is a form of self-alienation, which plástica can correct. 
For some women aging not only creates a gap between an ageless self and an aged body, but also pushes them into a new social role that they reject. Tatiana said that already in her 50s she was being called "minha senhora," a more formal form of address:

There are men with white hair, for example, with the biggest charm, but women . . . they already become "minha senhora." This is crazy. Women they develop earlier. This is something genetic ... Women become sort of matronly, they get fatter, here [in Brazil]. At 13 years old they're already menstruating, with a woman's body ... Because women are the generators of life, they have a hormonal factor, a different physical formation.

While she acknowledges a social double standard for men and women, her account of women's aging stresses biological differences (genetics, menstruation, reproduction, hormones), which in turn require more medical management.

Medical discourse sometimes stresses that historical changes have made aging a more problematic domain of psychosocial life. Dr. Barretto argues that medical progress expanded the life span from 35 years a century ago to between 80 and 90 today, which in turn has caused a "disequilibrium" between the mind and body. Plástica can correct this historically "new" problem: "It's more than normal to try to make the physical organism fit our interior youth, which is becoming more and more prolonged" (Plástica \& Beleza, May/June 1999, 203). Plástica is often presented as a new technology that enables women to negotiate the specific challenges presented by contemporary life.

This medical discourse recalls the representation of experiences of aging in "postmodern" societies made by some scholars. Featherstone and Hepworth (1991) describe a "mask of aging," a kind of self-alienation where the inwardly young consumer ceases to identify with an outwardly aged appearance. Similarly, Katz and Marshall (2003) discuss how new aging ideals address a "timeless" consumer who is trapped in an aging body (Katz and Marshall 2003). Plastic surgery could be said to reflect aspirations for a more "plastic" sense of identity not defined or limited by processes of biological aging. In the next sections I explore tensions in this psychotherapeutic project. I first discuss the social forces that address an "aging subject" made responsible for maintaining a state of pyschological, reproductive and sexual health with a focus on aesthetics.

\section{The Psychological Subject of Anti-Aging Medicine}

Brazil's rise to "empire of the scalpel," as a news magazine boasted, coincided with larger changes in social constructions of aging in Brazil beginning in the 1980s. Imported from abroad, the terms "third age" (terceira idade) and later "successful aging" refer to the ideal of a sociable, healthy, productive lifestyle for the elderly (Leibing 2005, Debert 2011). More generally, a youthful lifestyle is being defined as a norm for an expanding portion of the population. "Successful" aging can refer not just to the avoidance of disease and infirmity but rather the active pursuit of health through a variety of therapeutic techniques.

As we've seen, plastic surgery is one such technique used to remedy low self-esteem and a disjuncture between appearance and the self. However, the psychological problems patients report can also be linked to a psychological subjectivity that has emerged as aging norms have changed in Brazil. Once a "young country," over the past fifty years Brazil experienced a rapid demographic transition. The percentage of elderly doubled as Brazil's fertility declined in the 1960s and 1970s and life spans were extended (Leibing 2005, 17). While the population aged, the elderly were also made socially visible as a population in new ways. For example, pension funds began conducting market research that contributed to the notion of a "gray market" with political and consumer muscle (Debert 2011).

Annette Leibing (2005) argues that beginning in the late 1970s aging has been removed from a Christian moral framework that emphasized a simple, ascetic life as the key to longevity. Seniors instead were constituted as a "national problem" as social workers and psychologists provided new interventions. New models of aging stress, though, that the elderly should not become wards of the state, but rather remain active in order to avoid biological decline and depression (Leibing 2005). New aging ideals have sparked a social movement and reflect new social and politial aspirations of the elderly. However, the promise of liberation from (internalized) ageism is potentially undermined by new forms of self-monitoring. 
Positive aging, of course, presumes an opposite: negative aging. Avoiding this fate-and the mental health problems that come in its wake - requires self-management. Leibing points out that messages about "positive aging" involve "techniques of the self" and a "psychologization" of daily life (Leibing 2011, 25). She argues that the notion of "selfesteem" (auto-estima) figures as a key term in pastoral programs aimed at seniors. Keeping sociable as well as thinking positively are recommended as a means to age well. Conversely, psychological problems are said to "accelerate aging" (Leibing 2011, 24). Plástica discourse reverses this formula: beauty work that slows aging becomes a means of avoiding psychological problems. The psychotherapeutic benefits of surgery are available throughout the life course, as a "Miss Third Age" beauty contest made clear. The rationale of this event was to "augment the self-esteem" of the elderly. The 1996 winner was "judged by her plastic surgery, elegance, and empathy with the audience" (among the prizes was additional plastic surgery) (Leibing 2005).

The rising popularity of plástica thus reflects the growth of a psychotherapeutic worldview and "psy-" institutions (Cruikshank 1996, Rose 1996). The notion of self-esteem can be seen as a "therapeutic technology" in that it morally authorizes the healing of healthy patients. Elizabeth Haiken (1997) points out that in the U.S. plastic surgeons in the early 20th century scorned "beauty" doctors in a bid to legitimate the specialty. The eventual acceptance of cosmetic surgery depended not just on improved surgical technique but also on psychological notions such as the "inferiority complex," and later self-esteem. From a technical term used in psychological research (Ward 1996) the term self-esteem entered into a range of everyday uses: self-help manuals, black social movements, mobilization around third age, and beauty industries (Edmonds 2009). In Brazil, for example, in the 1990s new magazines oriented towards "black" beauty practices and celebrities began to speak of "rescuing the self-esteem of the black Brazilian" (Filho Dias 2006, 4; Fry 2002).

In Brazil the term auto-estima, like "third age" and "successful aging," was originally imported. Its foreign status does not mean it was inauthentic, but differences in class, education and religiosity have shaped the dissemination of a psychotherapeutic ethos (Duarte 1986). Among the middle class and elite plástica is thriving in the "ruins" of psychoanalysis, and is often combined with, or else replaces, the older talking cure. In public hospitals the psychotherapeutic rationale for plastic surgery was also prevalent. Sonia, who was waiting on line to have abdominal plástica, said, "I think my " $\mathrm{I}$ " is going to really improve, because the important thing is your interior. If your head is good, you're going to look at yourself and feel good." She also, though, added another reason: "We [a gente] want to be beautiful for the husband, nê?" Like many women in public hospitals she often used the pronoun "a gente" (we) in place of the "eu" (I) more commonly used by middle class women. Other patients were not fully conversant with the psychological idiom of plástica, or else doubted or mocked it. Janaina had worked as a "mulata" (in her account a job description not a color term) in a samba show. When I asked her why she wanted liposuction, she said, "Look, I'm going to do this surgery not because I'm bad in the head, but because I'm bad in the body . . . I looked at myself in the mirror and I saw that I was a pig [porcaria]. It doesn't do to look at myself and say, 'hum, I'm sexy [gostosa]' if my eyes fight with my thoughts." Other women simply said that plástica was a "woman's thing" or "women's vanity." Some patients, like Dona Firmina, an illiterate woman in her 50s, showed up to consultations with a picture of an artista (celebrity). Such patients could discomfit surgeons who worried that patients "did not have the culture to understand that plastic surgery is a medical procedure."

Thus, while psychological rationales for having cosmetic surgery were widespread, patients also had many other concerns that entered into their decision-making. Some worried about getting fired because they were "old" or feared losing a partner. Others were motivated by modest aspirations to break into the service economy and escape their mother's fate of "working for a family" (a euphemism for employment as a maid). Some psychologists employed by surgeons to screen candidates (to turn away those suspected of being too emotionally disturbed to be satisfied with results) were concerned that women were replacing psychotherapy with plastic surgery. Yet plastic surgeons simply said that their techniques were more "effective" than the talking cure. And as one psychologist acknowledged, many working class patients - for whom talk therapy is not an option - simply "prefer surgery" (Edmonds 2010). 
Coached by surgeons, psychologists, or other patients, surgery candidates come to replace "bad" motives - such as the desire to look like an artista or secure a marriage - with "good" ones, such as "boosting self-esteem." Interactions in the clinic thus are didactic in that they train patients to describe "defects" in clinical terms. But they also teach a psychotherapeutic rationale for surgery and "open up" the body as a terrain of self-management. Plastic surgery is thus not only a socially validated means to heal the suffering psyche, it also reflects a notion of appearance as a psychic domain requiring therapeutic management. Yet while plástica promises to liberate the timeless consumer from what Glaucia called the "shell" of the body, it can also reinforce awareness of aging as inexorable biological decline as it becomes embedded in the female life course.

\section{Surgery-for-Life: Plástica and the Female Life Course}

One of the most significant and problematic aspects of cosmetic surgery is that it is often a lifetime therapy for women. It was rare to encounter a patient who had had only one operation or was not already at the time of her first surgery planning additional ones. Around 70 percent of patients are women, but plástica is also highly gendered in that surgeries are often timed to female lifecycle events.

A former president of the Brazilian Society of Plastic Surgery sketched out a "typical timetable" of surgeries that begins in adolescence:

Age 15 to 20: Breast reduction surgery

Age 20 to 25: Liposuction, even before marriage

Age 25 to 35: Breast-lifting and liposuction, to correct the sags and bulges that can come with child-bearing

Age 35 to 43: She waits a while and goes back to the academia (gym) for exercise

Age 43 to 50: Facial surgery, taking the opportunity to have some 'freshening' done on the body ("War on Fat: Rio Cultists: Good Looks at the Beach," Los Angeles Times, 8/15/87).

However, patients often discussed their operations not only in relation to a "need" defined by chronological age but in relation to significant age-related milestones: "becoming a woman" (in Brazil often celebrated at the 15th birthday party); childbirth and breast feeding; decisions to end reproductive life (often by tubal ligation); divorce; and menopause.
Plástica is often given to teens as a birthday present, especially the festa de quinze anos. While a variety of operations aim to make patients look younger, ironically women are rarely considered "too young" to have plástica. Carlos Garcia, ex-president of the Brazilian Society of Plastic Surgery, argued that at the age of 16 the body is already "formed" and "nothing prevents adolescents from seeking a new appearance. It's in the physiology text books" ("Reino das Formas Perfeitas," Época, 6/19/00). Another surgeon said that liposuctions "should only be performed four years after the first menstruation."

The ideal of successful aging holds out the promise of extending a youthful lifestyle into middle age and beyond. Yet, plastic surgery also pushes the "need" to manage the aging body into early adulthood. Surgeons say that younger patients are "better patients." Younger skin means a smaller chance of complications and better aesthetic results. At a plastic surgery conerence in Rio de Janeiro, a surgeon told me that "the wrinkles of the future are not going to be the wrinkles of the present, that is, very deep wrinkles ... plastic surgery is becoming more preventive." The rise in "preventive surgery" and higher numbers of adolescents and women in their 20s having surgery have likely contributed to a drop in the average age of the patient. In 1980, the average age of the cosmetic surgery patient was 55 years. Ten years later it had dropped to 40 and by 2000 it was only 35 ("Os Exageros da Plástica," Veja, 3/6/02). There are also few upper age limits for plastic surgery. Imagining a skeptical reader asking why an eighty year old would elect to have plástica, one surgeon asserted "to simply feel better, younger, a little over sixty perhaps." Rather than being presented as an "artificial" prolongation of youth, plástica is often seen as a "natural" means - provided it's done well - to age in a modern world.

Both facial and bodily surgeries are also linked to menopause. Márcia had been waiting ten months to have a second facelift. She discussed her motivation to have the operation: "When I began menopause three years ago, everything fell, fell really fast. Women age more quickly ... menopause, hormones, breast feeding, giving birth, everything deforms the stomach, your body . . . and domestic life too is wear and tear, stress. And also men demand more of us." While Márcia mentions gendered social roles, she stresses that plástica is a means of 
compensating "damage" blamed on women's "quicker" aging.

But the most important lifecycle events mentioned in relation to plástica are pregnancy, childbirth and breastfeeding. Breast surgery, abdominal surgery, and liposuction are said to correct flaccid skin or localized fat or else "lift" areas of the body described as acabado (finished), caído (fallen) or murcha (shriveled). This language reflects a clinical gaze - sometimes taken on by patients - that fragments the body. While the field of "aesthetic medicine" presents aging as a holistic biosocial process, clinical practices instead localize aging in body parts, some of which become pathologically or prematurely "aged." Plastic surgery, however, is often used not just once to correct a "defect," but is integrated into a larger management regime for reproductive and sexual life.

Now in her mid-40s, Cecilia lives a comfortable life in a condo in the South Zone of the city. She grew up, though, in one of the poorest Rio suburbs, raised by a mother who gave birth to her at age 15, never learned to read, and converted from Catholicism to an evangelical church. Cecilia studied psychology in university and has tastes she considers "moderna," which run from a love of French cinema to a simple and "relaxed" (in her mother's words) sense of fashion. On her living room book shelf stand the entire collected works of Freud, translated into Portuguese. She is now separated from her husband, a self-made man with whom she had three children. Talking about her multiple surgeries she often mentioned her reproductive and marital life.

While her mother blamed her for the end of her marriage -- "you let yourself go" (selargou)-Cecilia simply said, "We had grown apart." It was at this time, when she was in her late thirties, that she decided to have abdominal surgery and liposuction on her thighs and abdomen (followed by an additional liposuction operation some years later). She explained how the operations were designed in part to "correct" the effects of her three Caesarean births:

I did it on my belly, which had a very flaccid part due to the cesáreas. ... And the doctor made a cut a little bigger than the Caesarean scars, and took out that piece of meat that was really flaccid, without life, and then he sewed it up, and did the liposuction.

She explained that when she was pregnant with her third child, she began to think about having surgery. She wanted to combine the birth, which like the others would be a Caesarean, with a tubal ligation and a correction of abdominal "flaccidity." As with many other women, Cecilia timed her surgeries to the end of her reproductive life (due to tubal ligation) in part because of a concern that becoming pregnant again would "ruin" the effects of surgery. After her gynecologist told her, however, that he couldn't "fix her belly" during the birth since he was already "tying the tubes," she decided to postpone the plástica. A few years later she had combined liposuction and abdominal surgery to "repair" the Caesareans and reduce "localized fat" she had gained during her pregnancies.

Cecilia was not considered "vain" by family or friends and in any event, vaidade (vanity) has a neutral or even positive connotation of "self-care" in Brazilian Portuguese. Rather, her medical history reflects a more widespread, sometimes routine use of plastic surgery to manage reproduction and aging. Ob-Gyns refer patients to plastic surgeons after giving birth, reinforcing the idea that cosmetic operations are a "normal" aspect of women's health. Vaginal birth is said to cause sexual and aesthetic damage that can be avoided with Caesarean sections, which comprise more than 70 percent of births in some private hospitals (Rebelo et al. 2010, Carranza 1994). ${ }^{3}$ Plástica is also used to correct iatrogenic damage from C-section, but also to "compensate" for medical suffering since it is "good for the self." Women who are unable to acquire a C-section are often given episiotomy, ${ }^{4}$ an incision made in the perineal muscle during delivery, and later followed by the ponto de marido, the extra "husband's stitch," which aims to correct "vaginal trauma" (Diniz and Chacham 2004). ${ }^{5}$ Other women giving birth in public hospitals who are "denied" C-sections are offered cosmetic vaginal plástica as a "proxy" C-section, Emilia Sanabria (2011) found. Links between Ob-Gyn, plastic surgery -- and sometimes endocrinology too -- have helped to routinize an aesthetic approach to managing reproduction and aging within a highly interventionist medical culture (Edmonds 2010, 2013a).

Clinical practices themselves contribute to "producing" the age-related defect and a consciousness of aging as biological decline. The surgeon measures defects with surgical instruments or discusses them in technical language with the patient, which can lend them an 
objective existence. In public hospitals discussion of defects is often a pedagogical exercise performed for a room filled with residents. A senior surgeon will (gently) pinch the nose, pull the skin on the forehead, pick up and drop the breast to test for skin elasticity. Surgeons also use digital photography to measure the size of asymmetries or defects. In private clinics too surgeons frankly describe defects. Lídia spoke of one consultation: "I went with my sister. I said to the doctor I'm thinking of a lift. He said, 'you have to do it, you have to do it now.' He took me into another room and with a pincer, showed me all I had to do. He said 'Our Lady, you're finished [acabada].' The clinical description of defects though is often "softened" by gallant praise. When Lídia said she had told him she was afraid of having a "stretched face," he replied, "No, you're a beautiful girl [moça], it will be good."

I found it difficult to understand the effects of plástica on its ostensible therapeutic object: self-esteem. Some patients used superlatives, describing how they felt "marvelous," "super-happy," "super-woman." Others spoke in a more restrained manner of a boost to self-esteem. But many patients came back for repeat surgeries, to correct complications, for retoques (touch-ups), or simply because their aesthetic expectations were not met. Those who were satisfied often had additional surgeries later, either to counter new effects of aging or because they had perceived new defects. Ironically, their interactions in the clinic could also create a heightened awareness of flaws. Some surgeons said correcting one defect can accentuate another one, for example, a breast reduction can make the belly appear to protrude too much. In other cases the expert simply points out an asymmetry the patient had never perceived, but quickly learns to "see."

Patients and surgeons view plástica as a powerful means to overcome limits imposed by aging. Yet the "operable body" is embedded in the female life course as patients time surgeries to biosocial events. Thus, while plastic surgery reflects a view of the body as "plastic" malleable, manageable, improvable - it can heighten awareness of aging as a biological trajectory. In the next sections I explore this tension further by analyzing the use of medical therapies to maintain or enhance sexual wellbeing throughout the life course.

\section{Menopausal Playboys: Sexual Rights and Duties in Middle Age}

New models of aging have, of course, not simply replaced older ones. Positive images of the elderly are often presented with an underlying irony, Leibing (2011, 22) points out. For example, activity is represented as a sign of successful ageing, but activity among the elderly is often seen as "empty bustling." Contradictions in new ideals of aging are particularly salient in the area of sexual health and sexual "fitness."

The ideal of successful aging validates to some extent sexual activity among middle aged and older women as "healthy." For example, the Ministry of Health announced that " 86 percent of Brazilians are sexually active between 41 and 55, a higher proportion than the 66 percent among youth from 16 to 25 ("Sexo depois dos 40," Veja, 24/5/2000). An article in Época claimed that over the last 30 years women have "succeeded in transforming their bodies into sources of pleasure" ("Sem Medo dos 40," Época, 9/27/99). Celebrities too have played a role in defining a more "liberated" sexual norm for middle-aged women (Goldenberg 2002, 19).

The new media interest in what one magazine article termed "sex after 40," however, coincided with heavy promotion of medical or quasi-medical sex and beauty treatments. For example, a Veja news article on the "arsenal of middle age" touted the benefits of a range of therapies for "him and her": from Viagra and antidepressants to aphrodisiacs that "combat frigidity" to cosmetic surgeries. Such techniques enable the middle aged to have a "much more active sexual life" than their parents did. Plástica is sometimes explicitly presented as erotic enhancement for middle-aged women. For example, actress Ângela Vieira - who like many celebrities has publicly discussed her surgeries -- appeared nude in a magazine and was dubbed a "menopausal playboy" ("Sem Medo dos 40," Época, 9/27/99). ${ }^{6}$

Flávia, a working class woman in her 20s, is one admirer of such images. She said that she "loved" to read magazines like Playboy because she "loves to see the body," i.e. the nude bodies of female models. Plástica is sometimes positioned in this visual culture as way to achieve sexual fulfillment. Flávia's mother, Bete, said men "flirted" more and that they had more tesão (desire) 
after she had several plastic surgery operations. These assertions of sexual agency, however, contrast with the disgust, contempt or even fear expressed by male peers, husbands, partners, and sons of female patients. One TV viewer said he felt repulsed when he noticed the contrast between a 40-year old face and an "old, wrinkled hand." Another man was outraged by a patient who said she had decided not to breast feed in order not to "ruin" her breasts. Even positive depictions of sexuality in "older" women (where older is a category that encompasses ever younger women) often have an ironic tone. The term menopausal playboy is partly humorous, as is the separada malhada, a separated woman with toned muscles.

Katz and Marshall (2003) analyze how sexual fitness has become a "pivotal sex/age body-problematic" in the new ideal of successful aging. They argue that a more standardized life course has given way to a "postmodern life course" in which "timeless consumers" become responsible for transcending sexual decline. Men have recourse to Viagra and testosterone therapy while women have access to various hormonal therapies, and perhaps eventually, an arousal pharmaceutical. They conclude that "the discourses of positive aging have created the sexy ageless consumer as a personally and socially responsible citizen" (Katz and Marshall 2003, 12).

This ideal of the "sexy, ageless consumer," however, involves very different therapeutic techniques for men and women. Sexual fitness for men is often focused on "performance" and erectile function through diet, exercise and drugs; sexy means in this context, "feeling like having sex." Sexual fitness for women - perhaps especially in Brazil - has a remarkable focus on beauty; sexy means here "sexually desirable." As in other Western countries, women's magazines in Brazil are filled with tips on erotic techniques. However, sexual fitness is often "aestheticized" in that it focuses on the technical management of attractiveness throughout the life course.

Some patients see plástica as a means to explicitly enhance erotic allure. Many operations that make relatively minor changes promise to project the breasts or "contour" the waist, hips and buttocks to create a more "gostosa" (sexy) figure. One female surgeon was distressed to see more clients in their 20s who "were already beautiful" and wanted to become "more perfect." An aestheticized approach to sexual fitness is also apparent in the marketing of cosmetic genital surgeries. Medical discourse claims that these operations enhance women's sexual pleasure (by correcting "vaginal widening" following normal birth) (Cirurgia Plástica Íntima, 2006). This reasoning, in ways similar to discourses surrounding C-sections, promotes a view of childbirth as a process that puts women at sexual and aesthetic risk. Marketing discourse also claims that "aesthetic aspects" of the genitals are "increasingly important for self-esteem." ${ }^{7}$ Sexual fitness is thus a complex ideal and norm. It aims not only to boost self-esteem and libido, but also entails a norm of medically-managed, "aesthetically pleasing genitalia" (McCallum 2005, 226). Some patriarchal sexual norms -- such as the ideal of premarital virginity -- are in decline. On the other hand, these sexual norms resurface in an "aestheticized" form in revirginization genital surgery or in a management regime that views reproduction as a sexual and aesthetic threat.

To some extent anti-aging medicine seems to take seriously the sexual concerns of middle aged and elderly women, reflecting a shift from an older medical assumption that sexual decline was an inevitable and natural part of the life course (Marshall 2009). In Brazil it also, however, often normalizes beautification as a health aim throughout life course. Teenagers have access to the same techniques of self-optimization as adults. Women in their 20s, 30s, and 40s are "already" ageing and need preventive medicine. And all adults are potentially "falsely aged," requiring therapy to look as young as they feel. The liberatory promise of anti-aging medicine thus coexists with a new "positive" morality that makes sexual fulfillment a right, but which also entails a duty to medically maintain attractiveness to preserve family relationships, self-esteem, and even health itself.

\section{"Mom is a Snapshot of Me in the Future":} Aging in the Family

I have discussed tensions between the promise of a liberation from an aging body and a biologized experience of passage through the life course. I explore this point further by examining how women see themselves as being linked to female kin through a genetic inheritance that creates shared medical "needs." Plástica is often represented as a personal choice undertaken by the patient in private consultation with a physician. But during 
fieldwork I was struck that plastic surgery was often a family matter. Surgeons acknowledge that the most effective means of marketing is boca a boca, word of mouth, which is often from kin to kin. Mothers, grandmothers, aunts, sisters, daughters and cousins recommended surgeons to each other or accompanied each other during multiple visits to the hospital.

I met Flávia and her mother, Bete, at a private clinic. Both women live in a working class neighborhood in the Zona Norte. Now in her mid-20s Flávia was having a breast lift and liposuction to "correct problems" she attributes to childbirth. She said she could never afford the clinic's prices, but got a heavy discount through a personal connection. She spoke of the influence her mother had on her when she was a small child:

My mother here already had four plásticas, and so since I was really little I lived with plástica in the family, nê?

Because she did her nose, she did her eyes, she did the same breast surgery and lipo I am doing now. And I was with my mom through all these procedures.

Mothers can provide "inspiration" to have surgery, but they can also "map out" the daughter's future aging. She said: "I usually say to men, look at your mother-in-law to see what you're buying, taking home. Mom is a snapshot of me in the future."

Like many unmarried women, Flávia lived with her mother. Both women were separated from the fathers of their children and in Flávia's words were "in the market" (of dating):

In the past, a 40 year-old woman felt old and ugly. And she was traded for a younger one. But not these days. A 40 year-old is in the market competing with a 20 yearold because of the technology of plastic surgery. She can stretch [her skin], do a lift, put in silicone, do a lipo, and become as good as a 20 year old.

This description echoes the collapse of generational differences analyzed by gerontologists. Plástica "allows" women of different ages to enjoy sexual freedom, making chronological age less relevant. Figueira argues (1996) that in consumer capitalism family members become less identified with age-defined roles. For Flávia, rather than being defined relationally through different rights and duties, mother and daughter become "equal" sexual beings, though situated in different moments of the aging process. This equality between the 40 year-old and 20 yearold though also puts them in a competitive relationship in a market, a point I return to below.
This mother and daughter pair stress the importance of "support" (força or apoio) they receive from each other. ${ }^{8}$ Having plastic surgery can be seen as a kind of rite of womanhood, especially when it is linked to a key life event. Other kinds of beauty work, such as wearing make-up or dressing up, can be seen as form of passing on the "arts" of femininity across generations and perhaps a form of bonding between kin. But plastic surgery also targets a notion of "beauty" that is defined biologically -in terms of anatomy, reproductive processes, hormones, and secondary sexual traits (Edmonds 2013b). The mother "maps" the future because she provides the example of how to successfully manage aging, but also because, Flávia said, their bodies age in similar ways.

Patients spoke too of inheriting from kin combinations of ethnic traits that require surgical correction. For example, some women who identified as branca (white) or morena ("brown" or "brunette") said they inherited the shape of their nose from an Indian or black grandparent or great-grandparent. They sought rhinoplasty to narrow their nose and make it more in "harmony" with their face. Their comments point to the "plasticity" of Brazilian constructions of race and color, as well as color hierarchies that value white, or relatively white, brancina, facial features (Edmonds 2010: part II, Goldstein 2003). They also show how generations are linked through genetic inheritance that creates particular medical "needs."

Plástica also mediates the kin relation by making generational gaps less apparent, or even invisible. Flávia and Bete mentioned being mistaken for siblings. Flávia hoped that when her five-year old was grown up, strangers too would assume they were sisters: "Because my body will be so well-treated, so conserved, like my mom's is now." While the age gap separates mother and daughter into different family roles, aging also in a sense links them in a biological process that requires management.

Patients spoke of plástica in terms that echoed the postmodern life course, and seemed to support the thesis of a "de-chronologized life course." But one problem with this thesis - which some argue is a more general problem plaguing postmodern theories - is that it mirrors new ideologies about the social phenomena it depicts. Successful aging is promoted by plastic surgeons. Yet patients, not surprisingly, also had more ambivalent attitudes towards the psychosocial effects of aging and the 
possibility of managing them medically. Flávia saw Bete's surgeries as an "inspiration," yet her mother's aging is also a sign of her own inevitable decline. She said in front of Bete: "Aging is horrible. I try not to even think of how I'll be at 50." Mothers not only map the daughter's aging body, but also possible futures of relationships. Divorce and separation rates have been rising since divorce was legalized in 1976 in Brazil. The number of men aged 40 to 59 marrying women in their 20s doubled from 1978 to 1996 (Veja, 24/5/2000). Plástica was also practiced by women in happy marriages, where it could provoke "jealousy" in the husband. But in intimate conversations women often expressed anxieties about current relationships or hinted at hopes that surgery would rekindle a marriage.

Lídia said she had "done one plástica with each husband, this is now my third." While Flávia seemed reassured that plástica can make a 20 year-old woman as "good as" as a 20 year-old, Valéria -- who was divorced -- joked about men who "trade one woman of 40 for two of 20." Luisamar spoke more despairingly about the breakdown of relationships: "In the past man didn't separate. He had his lover, or lovers, but the family was sacred. This is changing ... Everyone separating. I think it's absurd, a man living 40,50 years with a woman, and then leaving her. It's a kind of cruelty. 40 years of marriage, and they marry a 20 yearold." Other women viewed plástica as a "compensation" for the loss of love or inability to have more children due to the end of a relationship. The self-work in plástica is thus not just a "private" therapeutic technique for calibrating mind and body, but also transpires in a world of uncertain familial and sexual relationships.

Plástica is not the only medical therapy used to manage sexual and "aesthetic" anxieties. In her ethnographic work in Bahia, Emilia Sanabria (2010, 2011, 2012) found widespread experimental uses of sex hormones. Compounding pharmacies offer hand-crafted implants that combine a variety of hormones, including testosterone. These are used for off-label indications: menstrual suppression, coping with work difficulties, and regulating mood, libido and sexual disposition, disposicão. Dubbed "beauty chips" by the media, implants are also said to have "aesthetic" effects, such as diminishing cellulite, improving skin elasticity, and avoiding weight gain. These therapies are presented as a means to greater "freedom." However, Sanabria argues, this promise is subtly blurred with the duty to maintain disposicão and diminish periods of sexual unavailability to partners. What appears to be a technique for sexual self-optimization can also be a means for managing sexual relationships.

Tensions between reproductive and sexual rights (and duties) also surfaced in conversations with plastic surgery patients. Tatiana saw plástica as a way to "have it both ways," enabling her to enjoy breast feeding (without worrying about "damage") while boosting libido. Maria José said that after becoming a mother, the "role of woman becomes secondary" - a problem again that can be solved with plastic surgery (her comment was taken from an interview in Ribeiro and Aboudib 1997). In these accounts plástica is a kind of modern technology that allows women to overcome the "split" between motherhood and sexuality, which Sandra Bartky (1990) argues characterizes patriarchal society. The highly interventionist approach to women's health in Brazil can also reinforce this split as it normalizes a view of reproduction and aging as biological processes threatening sexual and "asthetic" integrity. ${ }^{10}$

\section{Conclusion}

This article has approached plastic surgery as a window on tensions in aging and sexual norms. I began with a discussion of the thesis that the life course has been dechronologized in contemporary societies. To some extent plastic surgery patients live in social circumstances that support this thesis. Women are postponing motherhood in Brazil (as in other industrialized societies). Across the socioeconomic spectrum they are less defined by domestic and reproductive work as Brazil's economy grows and gender norms shift (to give just one example, while the vast majority of older surgeons were male, young residents in surgery are about half female). In consumer culture youth is an ever-expanding category -- a lifestyle more than a stage in the life course. And medical discourse portrays aging as a process that can be limited or transcended with the right psychological, health, and beauty work.

I have argued, however, that in some important respects the life course remains "chronological" as plastic surgery and other therapies are medically authorized as management techniques that accompany a woman through the life stages of adolescence, birth, breast feeding and menopause. Patients embrace plástica as a means to bridge the gap between a youthful interior and aged exterior; yet 
also compete in markets of sexual relationships where youth is a form of capital. Medical discourse valorizes "sex after 40" and women's sexual pleasure; yet practices focus on a notion of sexual fitness that emphasizes the technical control of "aesthetic damage." The timeless consumer can transcend some limits of the standardized life course, yet also have a heightened awareness of biological aging. Some patients praise plástica as a way to manage conflicts between maternal and sexual roles; yet these conflicts also contribute to the pursuit of health practices which have health risks.

The goal of successful aging is thus often shadowed by the prospect of a failed rejuvenation. Self-tinkering reinforced by medical authority has the potential to make patients even more conscious of aging as biological and aesthetic decline. It's true that some patients experience therapeutic effects from both cosmetic and reconstructive surgery. Medical treatments (e.g. cancer surgeries, gynecological surgeries, psychotropic drugs) often cause sexual and aesthetic damage, thus it is arguably more legitimate to correct such damage. However, the medical and psychological management of aging comes with considerable risks. Perhaps the greatest is that plástica often becomes "surgery-for-life": a therapeutic process that is entangled with life course events and necessary for healthy aging, healthy reproduction, and healthy sex.

\section{ACKNOWLEDGEMENTS}

Research was supported with grants from the Social Research Council, Princeton University, and a Woodrow Wilson postdoctoral fellowship.

\section{Notes}

1. One major plastic surgery center is located in Santa Casa de Misericordia hospital, which is run with a mix of charity funds and state subsidies. Unlike fully public hospitals where all medical services are free, it offers free reconstructive surgery, but charges a small fee to cosmetic surgery patients to cover costs of medical materials and anesthesia (surgeons receive no payment). Both Santa Casa and public hospitals attend mostly working class patients.

2. Price competition between surgeons in a crowded market combined with an international reputation for quality - also attracts medical tourists (Edmonds 2011).

3. A meta-study concludes that there is no evidence that "elective" C-sections, compared to vaginal birth, protect sexual health or result in a speedier return to sexual activity (Barrett et al. 2005).

4. Demand for C-sections, as well as for plastic surgery, is partly fueled by class dynamics since both these therapies are considered in some contexts as "modern" medical goods that have been normalized in healthcare for middle class women (Béhague et al. 2002, Edmonds 2010).

5. Medical studies dispute that the routine use of episiotomy has any health or sexual benefits (Belizán and Carroli 1998).

6. The news article held up the actress, a 47 year-old divorced mother, as an example of a generation of middle aged women who "give a new meaning to the phrase coroa enxuta" (literally "a crown in good shape," that is, a well-preserved, middle aged person).

7. Herbenick and Reece (2010) claim to have developed a new psychological research tool, the "Genital Self-Image Scale."

8. Similarly, another working class patient, Sonia, brought her teenage daughter, Taís, with her to the hospital. Sonia was waiting for abdominal surgery and at first I thought her daughter was there to give her moral support. Discussing her decision to have the operation, she said that her husband "supports" her just as she supports her daughter's decision. "It's her 15th birthday present, the nose. She doesn't want a party, she wants to make a "book" [in English, a fashion modeling portfolio] with a nose that makes her feel good."

9. Surgeons too reinforce a "racialized" aesthetics of aging. They argue that 'pure whites' have skin that ages more rapidly, while women with some African descent have a tendency to gain weight more easily.

10. Tensions between maternal and sexual roles have historical roots in modernity, perhaps especially in Latin societies that have been described as having a "Madonna/whore complex" (Yalom 1997). But this "complex" takes a specific form in Brazilian medicine. When an Ob-Gyn says to a woman after she has her first child, "You don't have to look like that," sexual fitness is reinforced as an aesthetic norm attainable through proper management.

\section{REFERENCES}

Barrett, Geraldine, Janet Peacock, Christina R. Victor, and Isaac Manyonda

2005 Cesarean Section and Postnatal Sexual Health. Birth. 32(4):306-311.

Bartky, Sandra

1990 Femininity and Domination: Studies in the Phenomenology of Oppression. New York: Routledge. 
Béhague, D. et al.

2002 Consumer Demand for Caesarean Sections in Brazil: Informed decision making, patient choice, or social inequality? BMJ 324 (7343):942-5.

Belizán, J. M., and G. Carroli

1998 Routine episiotomy should be abandoned. BMJ 317 (7169):1389.

Brückner, Hannay and Karl Ulrich Mayer

2005 De-Standardization of the Life Course: What Might it Mean? And if it Means Anything, Whether it Actually Took Place? In The Structure of the Life Course: Standardized? Individualized? Differentiated? Advances in Life Course Research, Volume 9. Pp. 27-53. Amsterdam: Elsevier.

Carranza, Maria

1994 Saúde Reprodutiva da Mulher Brasileira. In Mulher brasileira é assim, M. Muñoz-Vargas and S. Heleieth, eds. Rio de Janeiro: Rosa dos Tempos.

Cirurgia íntima feminina

2006 Webpages, www.vitalita.med.br, visited January 20, 2006.

Cruikshank, Barbara

1996 "Revolutions from within: self-government and selfesteem." In Foucault and political reason, eds. Andrew Barry, Thomas Osborne, and Nikolas Rose. London: University College London Press

Debert, Guita Grin

2011 The dissolution of adult life and youth as a value. Horiz. antropol. [online]. 2010, vol.5, no.se Porto Alegre.

Diniz, Simone and Alessandra Chacham

2004 "The Cut above" and "The Cut below": The Abuse of Caesareans and Episiotomy in São Paulo, Brazil. Reproductive Health Matters 12(23):100-110.

Duarte, Luiz Fernando

1986 Da Vida Nervosa (nas classes trabalhadoras urbanas). Rio de Janeiro: Jorge Zahar Editor/CNPq.

Edmonds, Alexander.

-- 2013a Can Medicine be Aesthetic? Disentangling Beauty and Health in Elective Surgeries. Medical Anthropology Quarterly 27(2) (accepted).

-- 2013b The Biological Subject of Aesthetic Medicine. Feminist Theory 14(1): 65-82.

-- 2011 'Almost Invisible Scars': Medical Tourism to Brazil. Signs 36 (2):297-302.

-- 2010 Pretty Modern: Beauty, Sex and Plastic Surgery in Brazil. Durham: Duke University Press.
-- 2009 Learning to Love Yourself: Esthetics, Health and Therapeutics in Brazilian Plastic Surgery. Ethnos 74(4):465489.

Featherstone, Mike and M Hepworth

1991 The Mask of Aging and the Postmodern Life Course. In The Body, Social Process and Cultural Theory M. Featherstone, M. Hepworth and B.S. Turner, eds. Pp. 371-389. London: Sage.

Freud, Sigmund

2003 The Uncanny. London: Penguin Classics.

Fry, Peter

2002 “Estética e política: Relações entre 'raça,' publicidade e produção da beleza no Brasil." In Nu \& vestido: Dez antropólogos revelam a cultura do corpo carioca, edited by Mirian Goldenberg. Rio de Janeiro: Editora Record.

Garcia, Julio

2007 Hormone administration in an aesthetic surgery practice: one surgeon's experience. Aesthetic Surgery Journal 27:212214.

\section{Goldenberg, Mirian}

2002 "Laços de família": novas conjugalidades na novela das oito. Web manuscript, accessed June 24, 2013. http:// miriangoldenberg.com.br/images/stories/pdf/lacosdefamilia.pdf

Goldstein, Donna

2003 Laughter Out of Place: Race, Class, Violence, and Sexuality in a Rio Shantytown. Berkeley: University of California Press.

Haiken, Elizabeth

1997 Venus Envy: A History of Cosmetic Surgery. Baltimore: Johns Hopkins University Press.

Held, Thomas

1986 Instituionalization and deinstitutionalization of the life course. Human Development 29(3):157-162.

Herbenick, Debra and Michael Reece

2010 Development and Validation of the Female Genital SelfImage Scale. The Journal of Sexual Medicine. Volume 7, Issue 5, pages 1822-1830.

Katz, Stanley and Barbara Marshall

2003 New Sex for Old: Lifestyle, Consumerism, and the Ethics of Aging Well. Journal of Aging Studies 17(1): 3-16.

Kohli, Martin

2007 The Institutionalization of the Life Course: Looking Back to Look Ahead. Research in Human Development 4(3-4): 253271. 
Kohli, Martin and Meyer, J. W.

1986 Social Structure and Social Construction of Life Stages. Human Development 29:145-149.

Leibing, Annette

2005 The old lady from Ipanema: Changing notions of old age in Brazil. Journal of Aging Studies 19: 15-31.

Macmillan, Ross

2005 The Structure of the Life Course: Standardized? Individualized? Differentiated? Advances in Life Course Research, Volume 9. Amsterdam: Elsevier.

Marshall, Barbara

2009 Rejuvenation's Return: Anti-aging and Remasculinization in Biomedical Discourse on the 'Aging Male.' Medicine Studies 1(3): 249-265.

McCallum, Cecilia

2005 Explaining caesarean section in Salvador da Bahia, Brazil. Sociology of Health \& Illness. 27(2):215-242.

Moody, Harry

1993 Overview: what is critical gerontology and why is it important? In Voices and Visions of Aging: Toward a Critical Gerontology. R. Cole et al., eds. Pp. xv-xvi. New York: Springer.

Rebelo, Fernanda, et al.

2010 High Cesarean prevalence in a national population-based study in Brazil: the role of private practice. Acta Obstetricia et Gynecologica Scandinavica 2010, 89(7):903-908.

Rabinow, Paul and Rose Nikolas

2006 Biopower today. Biosocieties 1:195-217.

Rose, Nikolas

2007 The Politics of Life Itself. Princeton: Princeton University Press.

1996 Inventing Our Selves, Cambridge University Press.

Sanabria, Emilia

2010 From sub- to super-citizenship: sex hormones and the body politic in Brazil. Ethnos 75(4): 377-401.

Sanabria, Emilia

2011 The body inside out. Social Analysis: The International Journal of Social and Cultural Practice 55(1): 94-112.

Sanabria, Emilia

2012 Le genre de la substance: pratiques hormonales et reconfigurations pharmaceutiques des identités sexuelles au Brésil. Clio Histoire, femmes et societies 37.
SBME

2011 Sociedade Brasileira de Medicina Estética. Webpages visited May 20, 2011. www.sbme.org.br/portal

Ward, Steven

1996 Filling the World with Self-Esteem: A Social History of Truth-Making. Canadian Journal of Sociology 21(1).

Yalom, Marilyn

1997 A History of the Breast. New York: Ballantine Book 